\title{
INTERAÇÕES SOCIAIS E CARACTERÍSTICAS PESSOAIS EM JOGOS DE ARREMESSOS NA EDUCAÇÃO FÍSICA INFANTIL
}

\author{
Vitor Antonio Cerignoni Coelho \\ Universidade Federal do Tocantins, Palmas, Tocantins, Brasil \\ Rute Estanislava Tolocka \\ Universidade Metodista de Piracicaba, Piracicaba, São Paulo, Brasil
}

\begin{abstract}
Resumo
Este estudo verificou se o meio ambiente produzido em jogos de arremesso propicia condições que favorecem as interações sociais e características pessoais do desenvolvimento infantil. Trata-se de um estudo exploratório realizado com 25 crianças entre sete e dez anos de idade que, durante a aula de Educação Física, realizaram três situações diferentes de jogos de arremesso. Os resultados mostraram que o contexto proporcionou a realização de habilidades motoras, relacionamentos interpessoais, vivência de papéis sociais e características pessoais positivas, revelando ser este um ambiente facilitador ao desenvolvimento infantil.
\end{abstract}

Palavras chave: Relações Interpessoais. Jogos e Brinquedos. Desenvolvimento Infantil.

\section{Introdução}

Embora o direito da criança ao jogo tenha sido reconhecido pela Organização das Nações Unidas na Declaração Universal dos Direitos da criança há mais de meio século (ONU, 1959) e esteja contemplado pelo Estatuto da Criança e do Adolescente (BRASIL, 1990), o espaço e o tempo para a criança jogar têm diminuído bastante nas últimas décadas, como apontado por Ferreira Neto (2007); Farias et al. (2010) e Reverdito et al. (2013). Isso torna ainda mais importante a oferta de jogos na escola.

O jogo pode ser entendido como: atividade lúdica, espontânea e natural ao ser humano (CAILLOIS, 1990; MARCELLINO, 1992; HUIZINGA, 1996); parte do processo de formação do pensamento, da linguagem, da aprendizagem e da interação com o meio (PIAGET, 1975; VYGOTSKY, 1984; FREIRE, 1997); pode ser visto também dentro do processo da pedagogia do esporte, aprendizagem de ações táticas e técnicas, situações- problema, trabalho em equipe (cooperação e competição) e respeito à regras (PAES; 1992; GARGANTA, 1998; BROTTO, 2002; SCAGLIA, 2005); e

Pensar a Prática, Goiânia, v. 17, n. 3, p. 718-733, jul./set. 2014 
ainda como prática para desenvolvimento e aprendizagem de habilidades motoras e capacidades físicas (TANI et al. 1988; GALLAHUE e OZMUN, 2003).

Jogar, entre outras coisas, possibilita o exercício de habilidades motoras, as quais são essenciais para a realização de diferentes tarefas esportivas e cotidianas. Entre os diversos movimentos básicos necessários para uma melhor adaptação ao meio está a habilidade de arremessar por cima do ombro, que é essencial para a sobrevivência e o convívio social, desde os primórdios da humanidade, como nas atividades de caça ou guerra.

Estudos de Marques e Catenassi (2005) e Bento da Silva et al. (2009) sobre jogos referentes à habilidade de arremessar podem trazer contribuições para a participação em esportes, tais como handebol, beisebol e as provas de atletismo. No entanto, pouco se estuda sobre o meio ambiente propiciado pela participação da criança em tais jogos, o que pode desvelar outros aspectos do desenvolvimento infantil que estão envolvidos em tais atividades.

Uma possibilidade de estudos sob esta ótica pode ser encontrada na Teoria Bioecológica proposta por Bronfenbenner (1992, 1996, 2005), que divide os diferentes ambientes que o homem frequenta em quatro contextos constituídos de maneira integrada: microssistema, mesossistema, exossistema e macrossistema, sendo que o microssistema é o ambiente mais imediato da pessoa (por exemplo uma sala de aula, ou a casa onde uma criança mora). Nele é possível observar interrelações sociais, papéis sociais, atividades realizadas e características da pessoa. Assim, situações de jogo podem ser consideradas como um microssistema e observadas para verificar os estímulos ao desenvolvimento infantil que elas propiciam.

Segundo Bronfenbrenner (2005), as interrelações sociais são estabelecidas pelas díadas (unidade básica de análise), que podem ser: de observação (quando duas pessoas apresentam atitude de aproximação, observação e curiosidade em suas ações, prestando atenção uma na outra); de participação conjunta (quando duas pessoas ou mais se relacionam mutuamente); e díadas primárias (quando o nível de envolvimento é alto e mesmo a pessoa não estando presente no local, influencia as atividades da outra). Estas, por sua vez, ainda podem evoluir para tríadas, têtradas e pêntadas. Os papéis sociais são definidos como a função desempenhada pela pessoa na sociedade, podendo ser imitados e representados na infância. As atividades realizadas com persistência temporal e significado para os indivíduos envolvidos são denominadas atividades molares, e as atividades que têm menor importância são as atividades moleculares.

As características da pessoa (atributos pessoais) são fatores que influenciam as interações sociais, os papéis e atividades nos diferentes contex-

Pensar a Prática, Goiânia, v. 17, n. 3, p. 718-733, jul./set. 2014 
tos, podem apresentar atitudes ativas e passivas, positivas e negativas e são divididas em três tipos: disposições pessoais, consideradas como comportamentos que podem facilitar ou dificultar a inserção social da pessoa; recursos pessoais, que são as capacidades e habilidades do indivíduo para se adaptar ao ambiente; e as demandas pessoais, que são características que encorajam ou desestimulam as relações nos ambientes sociais (BRONFENBRENNER, 2005).

Desta forma, as características pessoais constituem ativos e passivos biopsicológicos com o poder de influenciar a capacidade das pessoas e os aspectos cognitivos, motores, afetivos, emocionais e sociais, ocupando efetivamente os processos de desenvolvimento. Estes processos podem desencadear, fortalecer ou enfraquecer as interações sociais dependendo dos acontecimentos que envolvem a pessoa, o processo, o contexto e o tempo que se deu para potencializar as relações. Sendo assim, as disposições, recursos e demandas se interrelacionam no sentido de gerar diferentes tipos de reações (positivas/ negativas) nas pessoas, causando mudanças nos ambientes vividos e nas atividades realizadas. (KREBS, 1997; 2003; 2009).

Tais pressupostos foram utilizados em diferentes estudos sobre o desenvolvimento infantil, observando situações de práticas de atividades físicas e lúdicas relacionadas a diferentes aspectos, dentre eles: variáveis antropométricas, desenvolvimento neuromotor, aspectos psicológicos (COPPETI, 1996; RAMALHO, 1996), ambientes lúdicos e aulas de Educação Física em escolas infantis (TOLOCKA et al. 2009; TOLOCKA e BROLO (2010), FARIA et al. 2010), além de fatores ambientais que interferem no desenvolvimento de bebês submetidos a intervenção motora (SPESSATO et al. 2009). Mas ainda são poucos os estudos que observam o jogo sob esta perspectiva.

Assim, os pressupostos desta teoria, relativos ao microssistema (aqui considerado como a aula de Educação Física) foram utilizados neste estudo com o objetivo de verificar se o meio ambiente produzido em jogos de arremesso propicia condições que favorecem as interações sociais e características pessoais do desenvolvimento infantil.

\section{Metodologia}

Este trata-se de um estudo exploratório e descritivo de abordagem qualitativa realizado em uma escola particular localizada em uma cidade do interior de São Paulo, com 25 crianças (18 meninas e sete meninos) entre sete e 10 anos de idade do Ensino Fundamental.

A aula de Educação Física foi considerada parte do meio ambiente natural onde estas crianças se inserem e foi ministrada pelo professor de Educação Física desta escola, com duração de 45 minutos, onde foi solicita-

Pensar a Prática, Goiânia, v. 17, n. 3, p. 718-733, jul./set. 2014 
do que as crianças realizassem três situações diferentes de jogos de arremesso:

1 - Durante 10 minutos a bola foi distribuída num canto do espaço da atividade, e foi solicitado às crianças que participassem juntas, realizando a tarefa de atravessar a quadra. Todas deveriam tocar em uma das seis bolas que estavam distribuídas no salão, sendo necessário que tanto a bola quanto o corpo das crianças estivessem em movimento.

2 - Durante 10 minutos o salão foi divido ao meio por uma corda. Em cada metade do salão foram colocadas oito bolas no chão. Cada criança escolheu um dos lados do salão para se posicionar. Foi sugerido que as bolas estavam em um "campo minado" e deveriam ser arremessadas para o outro campo. O campo que ficasse com o maior número de bolas seria explodido. Foram observadas apenas as situações onde as crianças realizaram arremesso por cima do ombro.

3 - Foram deixadas no salão cordas, arcos, bolas e fitas. Todas as crianças poderiam realizar as atividades que quisessem, utilizando ou não os materiais, durante 15 minutos. Nesta situação foram analisadas apenas as atividades que incluíram arremessos por cima do ombro.

Estas atividades foram registradas com quatro câmeras fixadas por um tripé em cada canto do salão, com espaço retangular medindo 15 × 8 metros, sem uso de zoom, cobrindo todo o espaço onde as atividades foram realizadas, além de uma câmera móvel.

As imagens foram transferidas para um computador com o software de captura e edição de imagens Movie Box 9.0, da Pinaclle Studio, que permite a observação quadro a quadro das imagens, em diferentes velocidades.

Os dados coletados foram transferidos para uma ficha de observação que continha: identificação da criança; características pessoais observadas durante a realização das atividades, tais como: disposições (curiosidade, iniciativa, liderança, participação, engajamento e empenho em atividades), demandas (capacidade atrair ou rejeitar atenção, afeto e relacionamentos); relações sociais estabelecidas; papéis sociais assumidos durante a atividade; atividades realizadas; classificação da atividade molar (significativa para a criança) ou molecular (sem significado para a criança); e materiais usados na atividade para que os dados pudessem ser analisados e quantificados.

Antes desta aula, para fins de observação de recursos pessoais dos quais as crianças dispunham, foram verificados o perfil antropométrico e o nível de habilidade motora de arremessar por cima do ombro.

O perfil antropométrico foi verificado a partir de medidas de massa corporal e estatura, de acordo com as normas da Organização Mundial da Saúde (WHO, 2006). Os valores obtidos foram comparados com os dados fornecidos pelo NCHS e Organização Mundial da Saúde citados no Manual

Pensar a Prática, Goiânia, v. 17, n. 3, p. 718-733, jul./set. 2014 
da Sociedade Brasileria de Pediatria (2009). Para os valores de massa corporal, estatura e Índice de Massa Corporal- IMC, as crianças foram classificadas em: desnutrição, baixo peso, eutrófico, sobrepeso e obesidade.

A avaliação do nível da habilidade básica de arremessar por cima do ombro foi de acordo com Roberton e Halverson (1984); Langendorfer e Roberton (2002). Os critérios variam entre os níveis iniciante, intermediário e avançado e referem-se a cinco ações a serem observadas no momento do arremesso: 1 - ação do tronco; 2 - balanço preparatório do braço para trás; 3 ação do úmero; 4 - ação do antebraço; e 5 - ação dos pés. A classificação final foi dada por dois avaliadores diferentes com valores que variam de 1 a 4 , sendo extraída a média da pontuação.

Os responsáveis pelos participantes do estudo deram seu consentimento livre e esclarecido. A instituição autorizou a realização do estudo. A pesquisa foi aprovada pelo Comitê de Ética em Pesquisa da UNIMEP, com parecer no. 76/03.

\section{Resultados e Discussão}

As relações interpessoais se intensificaram com o passar do tempo, durante a aula, tendo sido registradas 61 relações interpessoais de observação conjunta, onde as crianças se entreolhavam na tentativa de estabelecer alguma interação social ou participar da atividade com os colegas. Posteriormente, as atividades ocorreram em parceria com outras crianças, sendo registradas 72 atividades grupais, com predomínio das díadas (42 díadas, 17 tríadas, 8 tétradas e 5 péntadas).

Ao observar este contexto natural da criança, verificou-se que no início das atividades da aula as relações interpessoais se deram pelas díadas de observação, sendo consideradas como ponto de partida para a evolução das interações. Ocorreram, assim, as díadas de participação conjunta que se estenderam para tríadas, tétradas e péntadas de participação conjunta, isto é, grupos de duas, três, quatro, cinco e até seis crianças brincando e arremessando juntas por mais tempo.

Durante os jogos de arremesso, as interações de participação conjunta prevaleceram sobre as de observação. Neste caso, as atividades lúdicas de arremesso facilitaram os vínculos sociais e o envolvimento das crianças, proporcionando o desenvolvimento da formação de grupos. Quando as participações e interações aumentaram, as díadas de observação se tornaram um recurso para fortalecer as díadas de participação conjunta, solidificando a construção de grupos sociais durante as brincadeiras, possibilitando a vivência dos papéis sociais. Este contexto também foi observado nos estudos de Faria et al. (2010) e Brolo e Tolocka (2010) que mencionaram que as día-

Pensar a Prática, Goiânia, v. 17, n. 3, p. 718-733, jul./set. 2014 
das de observação são o ponto de partida para conquistar novos vínculos sociais.

Os papéis sociais observados se relacionaram com as brincadeiras que as crianças propuseram. Houve cooperação de algumas crianças que incentivaram os colegas a participarem das brincadeiras. Foram observados papéis de chefe, pegador, fugitivo, jogador de futebol, soldados do campo minado e vendedora, relacionados aos jogos realizados. Na pesquisa de Tolocka et al. (2009) as crianças que participavam das aulas de Educação Física a partir de atividades lúdicas também manifestaram papéis sociais de soldado, pegador, polícia e ladrão, ligados diretamente às brincadeiras realizadas. A ludicidade estimula o simbolismo infantil e revela um ambiente propício para vivenciar as relações entre real e imaginário, ao mesmo tempo em que a criança vai descobrindo a diferença nesta relação.

As atividades que tiveram maior persistência temporal e participação da maioria das crianças foram as que se aproximaram da proposta dos jogos oferecidos: trocas de passes em grupo com a bola atravessando a quadra (10 minutos), arremessar a bola para outro campo (10 minutos), mirar e acertar a bola dentro do arco em movimento (5 minutos), exploração do arco (5 minutos), passar a bola e trocar de arco (5 minutos).

Outras atividades aconteceram durante o momento livre: pega-pega (2 minutos), passar e pular o corpo dentro do arco ( 2 minutos). Dentre todas as atividades, uma brincadeira de futebol, onde três meninos começaram a trocar passes chutando a bola ocorreu de forma significativa durante a situação livre, quando as crianças ficaram sete minutos brincando. Esta brincadeira permitiu a vivência de papéis sociais de jogadores de futebol. Para Bronfenbrenner (2005) a influência cultural dentro do macrossistema também provoca alterações no comportamento das crianças, e na infância dos meninos brasileiros o futebol é uma atividade de destaque.

Estes papéis sociais encontrados no ambiente sustentam a afirmação de Bronfenbrenner (2005) na qual as atividades que são significativas para as crianças são muitas vezes acompanhadas por representações de papéis, incentivando a participação e a execução de habilidades.

Entre as características pessoais das crianças observadas durante os jogos, foram encontradas disposições pessoais geradoras (10 situações) e disruptivas, recursos positivos e negativos e demandas positivas (2 situações) e negativas (3 situações).

Foram observadas sete situações durante as três atividades em que as crianças convidaram seus colegas para brincar, formando os grupos de interação social, onde elas revelaram disposição geradora de iniciativa e liderança organizando seus grupos nos três momentos distintos da aula. Esta atitude estimulou a participação das crianças no ambiente lúdico.

Pensar a Prática, Goiânia, v. 17, n. 3, p. 718-733, jul./set. 2014 
Foram observadas demandas positivas quando duas crianças que não encontravam um grupo para participar da primeira atividade percorreram o espaço da aula se convidando para brincar com a bola até encontrarem um grupo que as acolhessem. Isto fez do ambiente um local que propiciou a autonomia de escolha das crianças, pois estas mudaram de grupo quando não satisfeitas com o desempenho motor ou aceitação do próprio grupo e dos seus integrantes. Nesta situação, as crianças apareceram observando o que mais lhes chamava a atenção e qual dos grupos lhes deixava participar da realização do jogo, para que seus objetivos fossem atingidos e pudessem executar o arremesso na brincadeira do campo minado.

Durante a segunda atividade foram observadas três situações com duas crianças distintas que apresentaram disposições geradoras de iniciativa, curiosidade e autonomia, trocando de grupo na tentativa de estabelecer melhores vínculos sociais.

Estas atitudes positivas são importantes para motivar e encorajar a criança no ambiente em que está inserida, a fim de executar o movimento exigido na tarefa e participar ativamente das atividades propostas em aula. Isso favoreceu a execução do arremesso com alegria e êxito e fez com que estas crianças interagissem entre si. Durante as brincadeiras aconteceram situações onde as crianças orientavam e corrigiam seus colegas em relação às regras do jogo e aos movimentos realizados.

Em determinados momentos a atividade proporcionava ações individualizadas do arremesso, como na atividade do campo minado, quando as crianças lançavam as bolas que caíam em seu campo e precisavam retirá-las e arremessá-las para o outro lado da quadra. Como a tarefa exigia dedicação específica para o êxito do grupo, proporcionava uma experiência prática que pode levar ao aprimoramento da habilidade de arremesso. Bronfenbrenner (1992; 1996) explica que esta situação contribui para evoluir o desenvolvimento secundário das crianças que executam a tarefa sem auxílio de outros, propiciando a conquista da autonomia.

Em três situações de demandas negativas, cinco crianças não estavam conseguindo jogar com os colegas, pois não foram convidadas por nenhum grupo. Elas, então, tentaram entrar em alguns grupos, mas os colegas as rejeitaram dizendo: "aqui na nossa equipe não há espaço para mais ninguém". Esta situação ocorreu quando participavam das atividades 1 e 3 .

Em relação aos recursos pessoais, a classificação do estado nutricional obtida através do IMC apontou nove meninas como eutróficas, quatro com sobrepeso, outras quatro com obesidade e uma com desnutrição. Entre os meninos, seis crianças foram classificadas como eutróficas, e apenas uma com obesidade. Assim, a maioria das crianças está dentro do esperado para a

Pensar a Prática, Goiânia, v. 17, n. 3, p. 718-733, jul./set. 2014 
faixa etária, segundo as referências da Organização Mundial da Saúde (OMS, 2006).

O nível de habilidade para a execução do arremesso foi considerado intermediário para a maioria das crianças. Segundo o estudo de Roberton e Langerdorfer (2002) que apresenta a sequência de nível de desenvolvimento da habilidade de arremessar por cima do ombro, as crianças deste estudo já deveriam estar em níveis avançados de movimento, aptas à prática de atividades motoras mais complexas. Porém os dados revelam que o nível motor das mesmas precisa evoluir. A Tabela 1 mostra os resultados individuais, tanto relativos ao IMC, quanto ao nível de habilidade motora de arremessar.

Tabela 01 - Recursos pessoais e relacionamentos interpessoais

\begin{tabular}{llllcc}
\hline $\boldsymbol{G} \boldsymbol{e}$ & $\boldsymbol{C} \boldsymbol{c}$ & $\boldsymbol{M N H}$ & $\boldsymbol{E N}$ & $\boldsymbol{R}-\boldsymbol{O}$ & $\boldsymbol{R P C}$ \\
\hline F & 1 & 2.6 & Obesidade & 1 & 5 \\
F & 3 & 2.4 & Sobrepeso & 9 & 10 \\
F & 4 & 2.0 & Eutrófico & 5 & 8 \\
F & 5 & 3.2 & Eutrófico & 1 & 7 \\
F & 6 & 2.4 & Sobrepeso & 2 & 8 \\
F & 7 & 1.4 & Obesidade & 7 & 4 \\
F & 8 & 2.2 & Eutrófico & 5 & 7 \\
F & 9 & 2.4 & Eutrófico & 2 & 8 \\
F & 10 & 2.6 & Eutrófico & 1 & 6 \\
F & 12 & 3.0 & Eutrófico & 3 & 10 \\
F & 13 & 2.2 & Eutrófico & 2 & 15 \\
F & 14 & 2.4 & Obesidade & 4 & 9 \\
F & 15 & 2.0 & Desnutrido & 3 & 10 \\
F & 16 & 2.2 & Eutrófico & 8 & 8 \\
F & 17 & 2.2 & Sobrepeso & 7 & 7 \\
F & 23 & 2.4 & Sobrepeso & 2 & 8 \\
F & 24 & 2.2 & Obesidade & 0 & 1
\end{tabular}

Pensar a Prática, Goiânia, v. 17, n. 3, p. 718-733, jul./set. 2014 


\begin{tabular}{lllllc}
$\mathrm{F}$ & 25 & 1.4 & Eutrófico & 0 & 2 \\
$\mathrm{M}$ & 2 & 2.6 & Eutrófico & 5 & 13 \\
$\mathrm{M}$ & 11 & 3.4 & Obesidade & 5 & 9 \\
$\mathrm{M}$ & 18 & 3.4 & Eutrófico & 4 & 6 \\
$\mathrm{M}$ & 19 & 3.4 & Eutrófico & 5 & 7 \\
$\mathrm{M}$ & 20 & 3.2 & Eutrófico & 7 & 7 \\
$\mathrm{M}$ & 21 & 2.6 & Eutrófico & 10 & 3 \\
$\mathrm{M}$ & 22 & 3.4 & Eutrófico & 3 & 9 \\
\hline
\end{tabular}

Legenda: Gênero (Ge); Criança (Cc); Média do Nível de Habilidade (MNH), Estado Nutricional (EN) Relacionamentos de Observação: díadas, tríadas e etc (R-O), Relacionamentos de Participação Conjunta: díadas, tríadas e etc (RPC).

Observa-se assim que, das nove crianças com excesso de peso, apenas uma (criança 11) encontra-se em nível avançado de desenvolvimento da habilidade de arremessar, o que é um indício de que o estado nutricional pode interferir no nível habilidoso da pessoa, se tornando um recurso negativo, como já apontaram os estudos de Okely, Booth e Chey (2004); Goodway, Crowe e Ward (2003); Bigotti e Tolocka (2005) e Berleze, Haeffner e Valentini (2007). Isso dificulta a realização de movimentos e favorece a rejeição dos colegas durante a participação da criança em atividades motoras.

Observando as crianças que não acompanharam os índices esperados de crescimento, verificou-se que elas não foram convidadas a participar com os colegas das atividades, principalmente as crianças 7, 21 e 24, que também apresentaram menor nível de habilidade motora. Tais crianças reclamavam constantemente que os colegas não queriam brincar com elas, e necessitavam da orientação do professor mesmo quando apareciam durante a atividade e pediam para brincar, mas eram rejeitadas. Este fato limitou a participação das mesmas e o seu desempenho nos jogos de arremesso, podendo ser considerado como recurso de caráter negativo para a participação e estímulos no ambiente.

As filmagens revelaram ainda que seis crianças $(7,18,19,21,24$ e 25) apresentaram dificuldades e problemas relativos a interações sociais e níveis de habilidade motora desenvolvida para realizar e participar das atividades de arremessar. Isto pode ter ocorrido por conflitos e discussões que 
essas crianças enfrentaram durante as atividades e não souberam resolver. Para Campos e Macedo (2011), o jogo é uma valiosa atividade para o envolvimento, orientação e mediação de situações-problema que a criança pode enfrentar nos ambientes que frequenta.

Vê-se que os recursos negativos das crianças prejudicaram suas demandas quando elas deixaram de participar e de interagir com os colegas. Assim, as possibilidades motoras foram limitadas pela falta de interação social e do incentivo às atividades lúdicas e vice-versa, mostrando relação entre os recursos pessoais, relacionamentos interpessoais e participação no jogo.

As relações destes diferentes aspectos podem interferir nos comportamentos das crianças, como o baixo nível de habilidade que dificulta a participação, interação e execução das atividades de arremesso, fazendo com que os colegas pouco as convidem a participar e se envolver nas brincadeiras, pois o insucesso na execução do movimento não contribui com o grupo. Como observou Bronfenbrenner (2005), os recursos pessoais interferem positiva ou negativamente nos processos de obtenção de êxito e sucesso, incluindo as tarefas motoras desempenhadas nos mais diferentes ambientes.

Neste sentido, destaca-se que a interação destes fatores pode estar ligada ao processo de desenvolvimento da criança, podendo comprometer negativa ou positivamente as interrelações sociais, papéis, características e atividades na infância. Este fator também foi mencionado nas pesquisas de Faria et al. (2010) e Tolocka et al. (2009) que, observando o cotidiano e as atividades realizadas por instituições infantis, identificaram que são poucas as possibilidades de atividades físicas oferecidas às crianças e que isto vem influenciando vários aspectos do desenvolvimento, entre eles: os relacionamentos sociais, as disfunções metabólicas, como obesidade, e os déficits em habilidades motoras. Tal fato privilegia o sedentarismo e a falta de estímulos à prática de atividades físicas, no caso das crianças, atividades lúdicas (jogos e brincadeiras).

Para Bronfenbrenner (2005) e Krebs (2009), fatores ambientais, da tarefa e do próprio indivíduo podem ser determinantes durante as atividades do cotidiano infantil. As análises mostraram que as restrições estruturais e funcionais (características da pessoa) que modificaram as ações de arremesso por cima do ombro foram: distância dos alvos a serem acertados; distâncias dos colegas para quem a bola ia ser passada ou jogada; interferências de outras crianças no momento do arremesso; formas diferenciadas de resolver a tarefa; diferentes possibilidades de execução do arremesso frente às exigências que a tarefa ou o ambiente oferecia; influência das relações sociais estabelecidas; e as características das crianças e os comportamentos emocionais associados ao sucesso e insucesso durante os jogos de arremesso.

Pensar a Prática, Goiânia, v. 17, n. 3, p. 718-733, jul./set. 2014 
Bronfenbrenner (2005) ainda explica que as modificações nas habilidades ocorridas pelos acontecimentos de uma dada situação podem representar o processo descontínuo que ocorre com o desenvolvimento, passando por momentos de instabilidade e estabilidade, criando condições para o indivíduo se adaptar às dinâmicas comportamentais. Neste estudo, a falta de habilidade motora de alguns participantes pode estar ligada a recursos negativos da criança, prejudicando as suas condições e possibilidades de interação social e participação nos jogos.

\title{
Considerações Finais
}

Verificou-se que a prática de jogos de arremessar em uma aula de Educação Física Infantil pode propiciar um ambiente primordial de desenvolvimento, pois possibilita a vivência de recursos, demandas e disposições pessoais, papéis sociais, formação de relacionamentos interpessoais e a prática de habilidades motoras básicas, que são fundamentais para o desenvolvimento infantil.

Observou-se que a dificuldade na realização de habilidades motoras, bem como o excesso de peso podem influenciar negativamente no comportamento das crianças e de seus pares, sendo necessário que medidas de orientação e prevenção ao excesso de peso, além de mais jogos e atividades lúdicas sejam realizados nas aulas de Educação Física. Isso ampliará o tempo e o espaço da criança jogar para aprender, criar, interagir, explorar e se movimentar.

\section{SOCIAL RELATIONSHIPS AND PERSONAL CHARACTERISTICS IN GAMES OF THROWING IN PHYSICAL EDUCATION CLASS FOR CHIL- DREN}

\begin{abstract}
This study observed if the environment produced due to throwing games provides conditions that benefit social interactions and personal characteristics regarding child development. This is an exploratory study done with 25 children between the ages of seven and ten, in which the children participated in three different throwing games in their physical education class. The results showed that the context provided the achievement of skills, interpersonal relationships, experience of social roles, displays positive and personal characteristics, revealing that such environment is favorable to child development.
\end{abstract}

Keywords: Interpersonal Relations. Play and Playthings. Child Development.

Pensar a Prática, Goiânia, v. 17, n. 3, p. 718-733, jul./set. 2014 


\title{
RELACIONES INTERPERSONALES Y CARACTERÍSTICAS PERSONALES EN JUEGOS DE LANZAMIENTO EN LA EDUCACIÓN FÍSICA INFANTIL
}

\begin{abstract}
Resumen
Este estudio analizó si el medio ambiente producido por juegos de lanzar proporciona las condiciones que favorecen las relaciones interpersonales y las características personales del desarrollo del niño. Se trata de un estudio exploratorio con 25 niños de entre siete y diez años de edad durante la clase de Educación Física realizaron tres juegos de lanzar en situaciones diferente. Los resultados mostraron que el contexto que proporciona el logro de habilidades, las relaciones interpersonales, la experiencia de los roles sociales, y las características personales positivas, revelando que el ambiente sea favorable para el desarrollo del niño.
\end{abstract}

Palabras-claves: Relaciones Interpersonales. Juegos y Juguetes. Desarrollo Infantil.

\section{Referências}

BENTO DA SILVA, S.; VILELA JUNIOR, G. B.; TOLOCKA, R. E. Arremessar por cima do ombro e a distância percorrida pelo implemento. Revista brasileira de Educação Física e Esportes, São Paulo, v. 23, n. 4, dez., 2009.

BERLEZE, A.; HAEFFNER, L. S. B.; VALENTINI, N. C. Desempenho motor de crianças obesas: uma investigação do processo e produto de habilidades motoras fundamentais. Revista Brasileira de Cineantropometria e Desempenho Humano. v.9, n.2, p.134-144, 2007.

BIGOTTI, S.; TOLOCKA, R. E. Desenvolvimento motor, gênero e medidas antropométricas em crianças na infância avançada. Temas sobre desenvolvimento. São Paulo, v. 14. n. 84, p.49-56, 2005.

BRASIL. Estatuto da Criança e Adolescente (ECA). Lei no 8.069, de 13 de julho de 1990, cap. II -art. 16 - par. IV, 1990.

BRONFENBRENNER, U. Ecological Systems theory. In: VASTA, R.. Six theories of child development: revised formulations and current issues. London: Jessica KingleyPublischer, p. 133-185, 1992. 
BRONFENBRENNER, U. A ecologia do desenvolvimento humano: experimentos naturais e planejados. Porto Alegre: Artes Médicas, 1996.

BRONFENBRENNER, U. The bioecological theory of human development .In: BRONFENBRENNER, U. (ed.). Making human beings human: Bioecological perspectives on human development. Sage Publication, Inc, p. 106-173, 2005.

BROTTO, F. O. Jogos cooperativos: O jogo e o Esporte como um exercício de convivência. $2^{\mathrm{a}}$ ed. Santos: Projeto Cooperação, 2002.

CAILLOIS, R. Os jogos e os homens. Lisboa, Cotovia, 1990.

CAMPOS, M. C. R. M.; MACEDO, L. Desenvolvimento da função mediadora do professor em oficinas de jogos. Psicologia escolar e Educacional. v.15, n.2, p. 211-220, 2011.

COPPETI, F. O desenvolvimento de crianças de teutonia, interpretado através do paradigma ecológico-humano. Dissertação (Mestrado em ciência do movimento) - Universidade Federal de Santa Maria, Santa Maria, RS, 1996.

FARIA, M. C. M. et al. Atividades motoras cotidianas e suas influências no desenvolvimento de pré-escolares. Movimento. v.16, n.1. p.113- 130, 2010.

FERREIRA NETO, C. O desenvolvimento da criança e a perspectiva ecológica do jogo. In: KREBS, R. J.; FERREIRA NETO, C. (Orgs.) Tópicos em desenvolvimento motor na infância e adolescência. Rio de Janeiro: LECSU, p. 92-103, 2007.

FREIRE, J. B. Educação de corpo inteiro: teoria e prática da Educação Física. $4^{\text {a }}$ Ed. São Paulo, SP: Scipione, 1997.

GALlAHUE, D.L; OZMUN, J. C. Compreendendo o Desenvolvimento Motor: em bebes, crianças, adolescentes e adultos. São Paulo: Phorte, 2003.

GARGANTA, J. M. S. O ensino dos jogos desportivos coletivos: perspectivas e tendências. Movimento. Porto Alegre/RS, Ano IV, nº, p.19 -27, 1998. 
GOODWAY, J.; CROWE, H.; WARD, P. Effects of motor skill instruction on fundamental motor skill development. Adapted physical activity quarterly. v. 20, nº 3, p. 298-314, 2003.

HUIZINGA, J. Homo ludens: o jogo como elemento da cultura. São Paulo: Perspectiva, 1996.

KREBS, R. J. A teoria dos sistemas ecológico: um paradigma para a educação infantil.Santa Maria: UFSM,1997.

KREBS, R. J. A criança e o esporte: reflexões sustentadas pela Teoria dos Sistemas Ecológicos. In: KREBS, R. J. et al. (Org.). Os processos desenvolvimentais na infância. Belém: GTR Gráficas e Editora, p. 91-99, 2003.

KREBS, R. J. Proximal processes as the primary engines of development. International Journal of Sport Psychology. v. 40, n. 1, p. 219-228, 2009a.

LANGENDORFER, S.; ROBERTON, M. A. Individual pathways in the developmental of forceful throwing. Research Quarterly for Exercise and Sport, v. 73, n. 3, p. 245-256, 2002.

MARCELlinO, N. C. Pedagogia da animação. $2^{a}$.ed. Campinas, Papirus, 1992.

MARQUES, I.; CATENASSI, F. Z. Restrições da tarefa e padrões fundamentais de movimento: uma comparação entre o chutar e o arremessar. Revista da Educação Física/UEM. v. 16, n. 2, p. 155-162, 2005.

ONU (Organização das Nações Unidas). Declaração Universal dos Direitos da Criança. Resolução da Assembleia Geral 1386 (XIV), 1959.

OKELY, A.; BOOTH, M.; CHEY, T. Relationships between body composition and fundamental movement skills among children and adolescents. Research Quarterly for Exercise and Sport. v. 75, n. 3, p. 238-247, 2004.

PAES, R. R. Aprendizagem e competição precoce: o caso do basquetebol. Campinas: UNICAMP, 1992.

PIAGET, J. A formação do símbolo na criança: imitação, jogo e sonho, imagem e representação. $2^{\mathrm{a}}$. Rio de Janeiro: Zahar, 1975. 
RAMALHO, M. H. O recreio pré-escolar e a motricidade infantil na perspectiva da teoria da ecologia do desenvolvimento humano. Tese (Doutorado em ciência do movimento). Universidade Federal de Santa Maria, Santa Maria, RS, 1996.

REVERDITO. R. S. et al. O cotidiano da criança na instituição de ensino: espaço e tempo disponível para atividades lúdicomotoras. Pensar a Prática, Goiânia, v. 16, n. 2, p. 320602, abr./jun. 2013.

ROBERTON, M. A.; HALVERSON, L. Developing children: Their changing movement. Philadelphia: Lea Tebiger, 1984.

SCAGLIA, Alcides José. Jogo: um sistema complexo. In: VENÂNCIO, S.; FREIRE, J. B. ( $\mathrm{Org}$.). O jogo dentro e fora da escola. Autores Associados, p. 37-69, 2005.

SOCIEDADE BRASILEIRA DE PEDIATRIA. Departamento de Nutrologia. Obesidade na infância e adolescência - Manual de orientação. São Paulo: Sociedade Brasileira de Pediatria, 116p, 2008.

SPESSATO, B. C. et al. Educação Infantil e intervenção motora: um olhar a partir da teoria bioecológica de bronfenbrenner. Movimento. v. 15, n. 4, 147-173, 2009.

TANI, G.; MANOEL, E. J.; KOKUBUN, E. Educação física escolar: fundamentos de uma abordagem desenvolvimentista. EPU/USP, 1988.

TOLOCKA, R. E.; BROLlO, A. L. Atividades físicas em Instituições de ensino infantil: uma abordagem bioecológica. Revista Brasileira de Cineantropometria e Desempenho Humano v.12, n.2, p. 140-147, 2010.

TOLOCKA, R. E. et al. Como brincar pode auxiliar no desenvolvimento de crianças pré-escolares. Licere, Belo Horizonte, v. 12, n. 1, abr., 2009.

VYGOTSKY, L. S. A formação social da mente: o desenvolvimento dos processos psicologicos superiores. Martins Fontes: São Paulo, 1984.

WHO child growth standards: length/height-for-age, weight-for-age, weight-for-length, weight-for- height and body mass index-for-age: methods and development. ONIS, Mercedes de. (Org.). Geneva: WHO, 2006. Disponível em: http://www.who.int/childgrowth/en/. Acesso em: 05/09/2011.

Pensar a Prática, Goiânia, v. 17, n. 3, p. 718-733, jul./set. 2014 
Agradecimento: Ao Prof. Dr. Ruy Jornada Krebs (In memórian) pela contribuição nesta pesquisa.

Recebido em: 04/04/2012

Revisado em: 08/10/2012

Aprovado em: 20/12/2012

Endereço para correspondência:

v7coelho@yahoo.com.br

Vitor Antonio Cerignoni Coelho

Fundação Universidade Federal do Tocantins, Campus Universitário de Miracema.

Av. Lourdes Solino s/n

Setor Universitário

77650000 - Miracema do Tocantins, TO - Brasil

Pensar a Prática, Goiânia, v. 17, n. 3, p. 718-733, jul./set. 2014 